\title{
Inhalatiecorticosteroïden bij COVID-19?
}

Jacoba Greving, Aimée Kok, Miesje Nijs, Ton Kuijpers, Margriet Bouma

Zijn inhalatiecorticosteroïden [ICS] aan te bevelen bij de behandeling van volwassen COVID-19-patiënten met klachten in de huisartsenpraktijk? De herziene NHGStandaard COVID-19 geeft een zwakke aanbeveling voor het gebruik van ICS voor een specifieke groep 50+'ers.

Onderzoeken naar patiëntkarakteristieken van opgenomen COVID-19-patiënten toonden een onverwacht laag aantal astma- en COPD-patiënten. ${ }^{1}$ Nadat laboratoriumonderzoeken lieten zien dat inhalatiecorticosteroïden (ICS) in staat waren om virusreplicatie van COVID-19 in de luchtwegen te verminderen, ontstond de hypothese dat ICS mogelijk een bijdrage kunnen leveren aan het voorkomen van klinische achteruitgang bij patiënten met COVID-19.

\section{SAMENVATTING VAN HET BEWIJS}

Yu et al. verrichtten een gerandomiseerd onderzoek (PRINCIPLE-trial) naar de effectiviteit van budesonide inhalatie bij COVID-19-patiënten met klachten in de huisartsenpraktijk. ${ }^{2}$ Patiënten met COVID-19-klachten ( $<14$ dagen) met een
Raadpleeg de volledige aanbeveling over ICS in de NHG-Standaard COVID-19 op https://richtlijnen.nhg.org/standaarden/covid-19.

hogere kans op complicaties (leeftijd $\geq 65$ jaar of $\geq 50$ jaar met comorbiditeit) werden gerandomiseerd over budesonide inhalatie (2 dd 800 microgram voor 14 dagen) of gebruikelijke zorg. Het onderzoek liet zien dat budesonide inhalatie waarschijnlijk de duur van de COVID-19-klachten met gemiddeld 3 dagen verkort. Daarnaast vermindert mogelijk de kans op ziekenhuisopname of overlijden (2\% lagere kans). Uit andere bronnen weten we dat het aantal gerapporteerde bijwerkingen van (kortdurend) ICS-gebruik laag is en de bijwerkingen mild zijn. Zie de [infographic] voor een overzicht van de absolute effectschattingen en de wijze waarop de aanbeveling voor ICS tot stand is gekomen. De aanbeveling [kader] en de doelgroep zijn gebaseerd op de resultaten en de onderzochte patiëntengroep van de PRINCIPLE-trial. Eerder werd al een gerandomiseerd onderzoek (fase 2) gepubliceerd over ditzelfde onderwerp met vergelijkbare resultaten. ${ }^{3}$

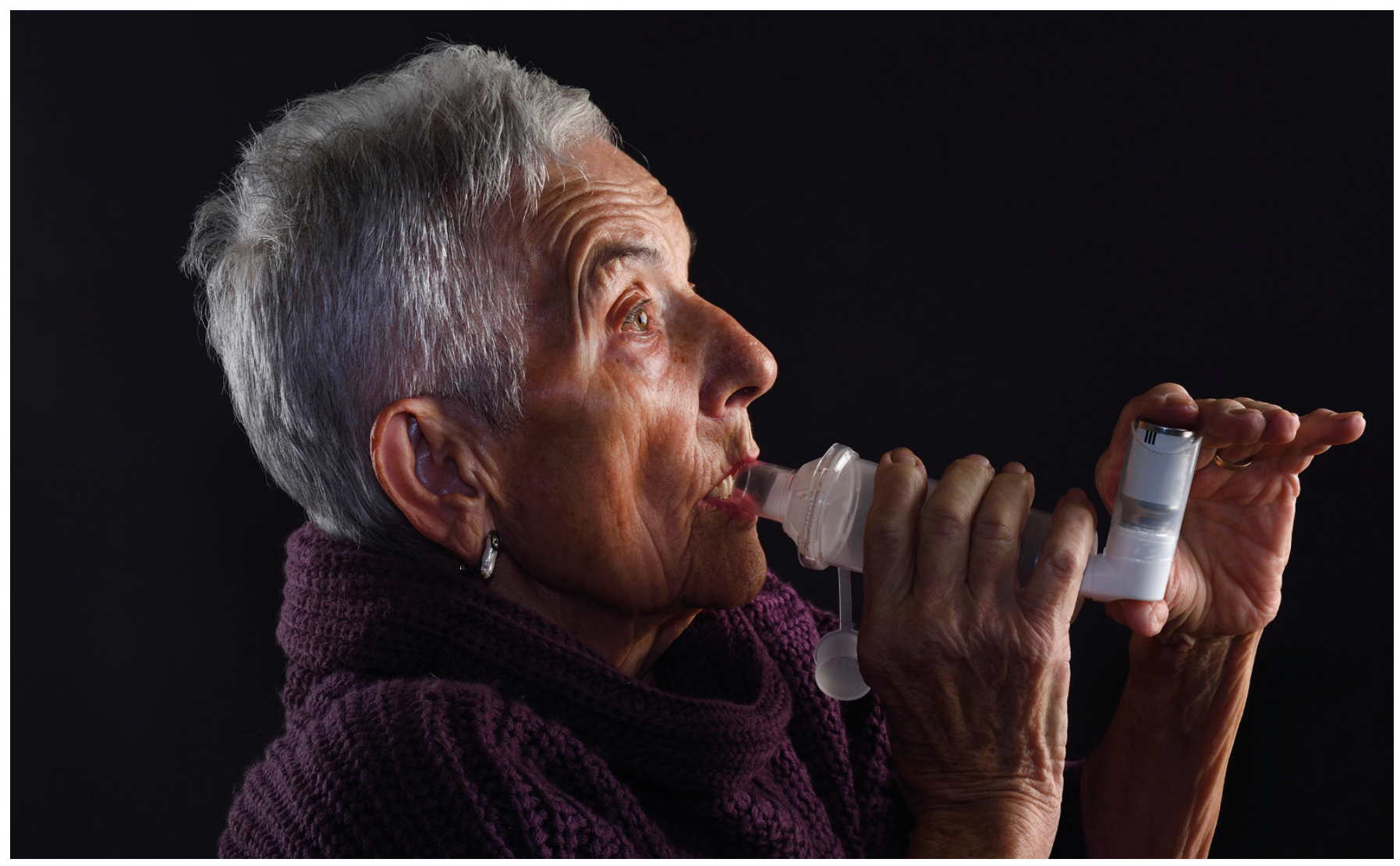

Budesonide inhalatie verkort waarschijnlijk de duur van de COVID-19-klachten met gemiddeld 3 dagen bij een specifieke groep $50+{ }^{\prime}$ ers. 


\section{Visuele samenvatting van de aanbeveling}

vs.

Gebruikelijke zorg

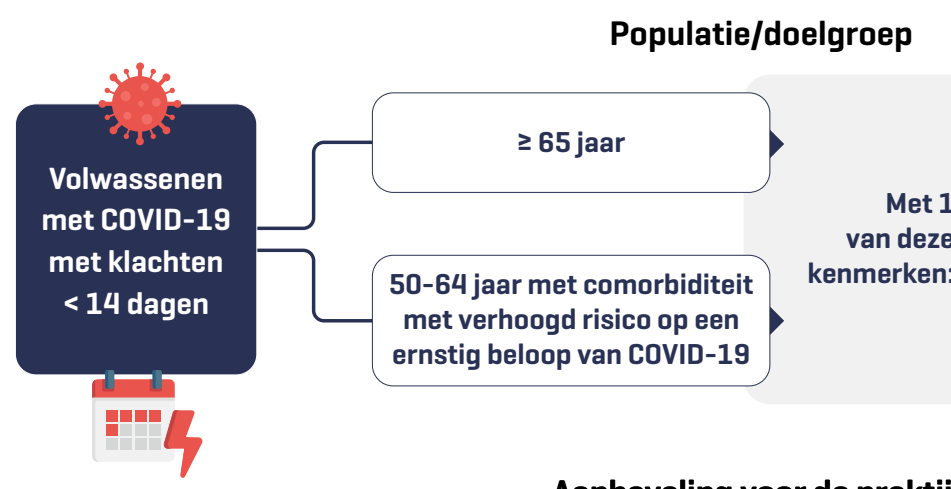

Aanbeveling voor de praktijk

Overweeg inhalatiecorticosteroïden bij patiënten met COVID-19 behorend tot de doelgroep.

Inhalatiecorticosteroïden

Sterk

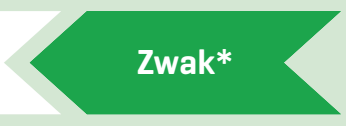

\section{Gebruikelijke zorg}

Zwak

Sterk

* De voordelen zijn groter dan de nadelen voor een meerderheid van de patiënten.

De meerderheid van de geïnformeerde patiënten zal waarschijnlijk deze optie kiezen.

\section{Praktische toepassing}

Geef bij de keuze voor een inhalatiecorticosteroïd een hoge dosering tot de klachten verdwijnen gedurende minimaal 7 en maximaal 14 dagen. Geef bij voorkeur budesonide inhalatie 2 dd 800 microgram.

\section{Vergelijking van de voor- en nadelen}

In het voordeel van inhalatiecorticosteroïden
Geen verschil
In het voordeel van gebruikelijke zorg

\section{Verwachte resultaten van de interventie [binnen 1 maand]}

\begin{tabular}{|c|c|c|c|c|}
\hline \multirow[b]{2}{*}{$\begin{array}{r}\text { Ziekenhuis- } \\
\text { opname/ } \\
\text { overlijden }\end{array}$} & \multicolumn{3}{|c|}{ verwacnte resultaten van de interventie [Dinnen 1 madna] } & \multirow{2}{*}{ [GRADE] } \\
\hline & $\begin{array}{l}\mathbf{6 8} \\
\text { per } 1000\end{array}$ & $\begin{array}{r}20 \text { minder } \\
\text { per } 1000\end{array}$ & $\begin{array}{c}\mathbf{8 8} \\
\text { per } 1000\end{array}$ & \\
\hline $\begin{array}{l}\text { Tijd tot aan } \\
\text { verdwijnen } \\
\text { klachten }\end{array}$ & $\begin{array}{l}12 \\
\text { dagen [mediaan] }\end{array}$ & $\begin{array}{r}2,9 \text { lager } \\
\text { dagen }\end{array}$ & $\begin{array}{c}15 \\
\text { dagen [mediaan] }\end{array}$ & \\
\hline
\end{tabular}

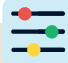

\section{Waarden en voorkeuren}

We verwachten dat het merendeel van de patiënten de mogelijke voordelen [verkorting van de klachtenduur en een lagere kans op ziekenhuisopname of overlijden] vindt opwegen tegen de kans op mogelijke bijwerkingen.

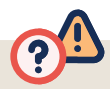

\section{Bijwerkingen}

De bekende bijwerkingen van [kortdurend] ICS-gebruik zijn mild. Ook het aantal gerapporteerde bijwerkingen van een hoge dosering in de studies is laag. 


\section{AANBEVELING}

Overweeg ICS voor te schrijven bij COVID-19-patiënten die contact opnemen met de huisarts vanwege klachten die $<14$ dagen bestaan en:

- $\geq 65$ jaar of

- 50-64 jaar met comorbiditeit met een verhoogd risico op een ernstig beloop van COVID-19

met 1 van deze kenmerken:

- niet [volledig] gevaccineerde patiënten responder' zijn

- overige gevaccineerde patiënten die ondanks vaccinatie matig-ernstige klachten ontwikkelen
- gevaccineerde patiënten die verondersteld 'non-

Een juiste inhalatietechniek is essentieel voor de behandeling. Geef daarom duidelijke instructies voor het gebruik. Adviseer de patiënt www.inhalatorgebruik.nl te raadplegen om de instructie en filmpjes te bekijken. Adviseer na gebruik de mond te spoelen.

\section{LITERATUUR}

1. Halpin DM, Faner R, Sibila O, Badia JR, Agusti A. Do chronic respiratory diseases or their treatment affect the risk of SARS-CoV-2 infection? Lancet Respir Med 2020;8:436-8.

2. Yu LM, Bafadhel M, Dorward J, Hayward G, Saville BR, Gbinigie O, et al. Inhaled budesonide for COVID-19 in people at high risk of complications in the community in the UK (PRINCIPLE): a randomised, controlled, open-label, adaptive platform trial. Lancet 2021;398:843-55.

3. Ramakrishnan S, Nicolau DV, Jr., Langford B, Mahdi M, Jeffers H, Mwasuku C, et al. Inhaled budesonide in the treatment of early COVID-19 (STOIC): a phase 2, open-label, randomised controlled trial. Lancet Respir Med 2021;9:763-72.

\section{WAARDEN EN VOORKEUREN VAN DE PATIËNT}

De verwachting is dat patiënten veel waarde hechten aan een verkorting van de duur van de COVID-19-klachten en een vermindering van het risico op ziekenhuisopname en overlijden. Dit weegt op tegen de kleine kans op milde bijwerkingen.

\section{PRAKTISCHE TOEPASSING}

Geef bij de keuze voor ICS een hoge dosering tot de klachten verdwijnen gedurende minimaal 7 en maximaal 14 dagen. Geef bij voorkeur budesonide inhalatie 2 dd 800 microgram. Deze aanbeveling geldt voor een specifieke doelgroep (zie [infographic]).

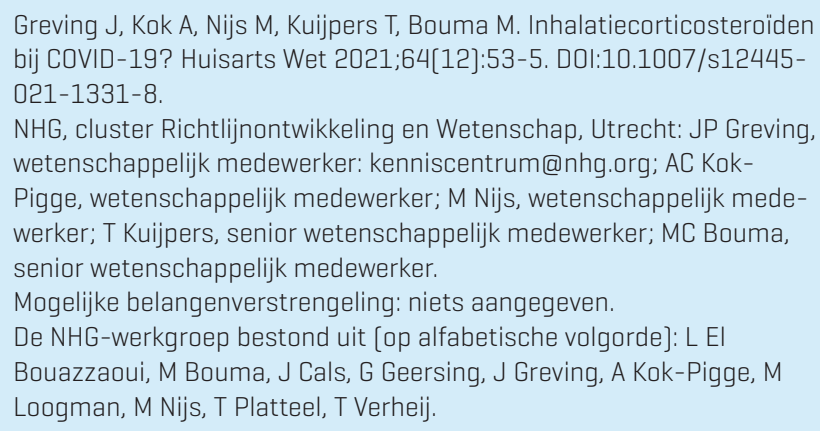
bij COVID-19? Huisarts Wet 2021;64[12]:53-5. D0I:10.1007/s12445021-1331-8.

NHG, cluster Richtlijnontwikkeling en Wetenschap, Utrecht: JP Greving, wetenschappelijk medewerker: kenniscentrum@nhg.org; AC Kok-

Pigge, wetenschappelijk medewerker; M Nijs, wetenschappelijk medewerker; T Kuijpers, senior wetenschappelijk medewerker; MC Bouma, senior wetenschappelijk medewerker.

Mogelijke belangenverstrengeling: niets aangegeven.

De NHG-werkgroep bestond uit [op alfabetische volgorde]: L EI

Bouazzaoui, M Bouma, J Cals, G Geersing, J Greving, A Kok-Pigge, M Loogman, M Nijs, T Platteel, T Verheij. 